\title{
The Prediction of Carbon Emissions Demands in India under the Balance Economic Growth Path
}

\author{
Shiyan Zhai ${ }^{1}$, Zheng Wang ${ }^{2}$ \\ ${ }^{1}$ Key Laboratory of Geographic Information Science, Ministry of Education East China Normal University, Shanghai, China; ${ }^{2}$ Institute \\ of Policy and Management, Chinese Academy of Sciences, Beijing, China. \\ Email: wangzheng@casipm.ac.cn, zsycenu@hotmail.com
}

Received April 20 ${ }^{\text {th }}$, 2012; revised June $6^{\text {th }}, 2012$; accepted June $13^{\text {th }}, 2012$

\begin{abstract}
Facing the challenge of climate change, forecasts of energy demand and carbon emissions demand are a key requirement for India to ensure energy security and the balance economic growth. The authors calculate the optimal economic growth under the balance economic growth path from 2009 to 2050 in India based on the economy-carbon dynamic model. Combination of Intergovernmental Panel on Climate Change (IPCC) 2006 edition of the formula of carbon emissions, energy intensity model, and population model, it gets the carbon emissions demand caused by energy consumption for time span 1980-2008. Then, it estimates the energy consumption demand and carbon emissions demand under the balance economic growth path from 2009 to 2050. The results show that the cumulative amount of energy demand and carbon emissions demand in India for the time span 2009 to 2050, are 44.65 Gtoe and 36.16 Gt C, separately. The annual demand of energy consumption and carbon emissions for India show an inverted U curve from 2009 to 2050. The demand of energy consumption and carbon emissions will peak in 2045, and the peak values are 1290.74 Mtoe and 1045.98 Mt C. Furthermore, India's per capita energy consumption demand and carbon emissions demand also appear maximum values, which are separately 0.81 toe and $0.65 \mathrm{t} \mathrm{C}$.
\end{abstract}

Keywords: Balance Economic Growth; Energy Intensity; Energy Consumption; Carbon Emissions

\section{Introduction}

Last 20 years, governments pay more attention to the series of environmental problems induced by global warming. In 2007, Intergovernmental Panel on Climate Change (IPCC) presented their opinion that global warming is mainly caused by the greenhouse gas emissions. Among various Green House Gases (GHG), anthropogenic carbon dioxide $\left(\mathrm{CO}_{2}\right)$ emissions through the combustion of fossil fuels appear to be the major contributor of global warming [1]. Facing the global challenge of climate change, the world has the responsibility to incorporate to negotiate the development measures to reduce greenhouse gas emissions [2,3]. In 2008, India was the second most populous country in the world, with the population of 1.14 billion. In addition, India is the sixth largest energy consumer and also one of the fastest growing energy consumption countries in the world. In the last five years, the average annual economic growth rate for India was $8.57 \%$. The rapid economic growth requires more energy consumption with adequately higher emission of Carbon. India faces formidable challenges in meeting its energy needs and providing adequate and diverse forms of energy of desired quality to users in a sustainable manner and at reasonable costs. With nearly $40 \%$ of the households classified as below the poverty line in the latest estimation [1], India needs economic growth for sustainable development, which in turn requires access to clean, convenient and reliable energy for all. Therefore, it is extremely important to predict India's energy demand and carbon emissions demand based on the balance economic growth to ensure attaining $8 \%$ $10 \%$ growth rate and increasing substantially.

There are many papers that focused on problems connected with the research of energy consumption and carbon emissions for India. The energy journal addressed various opinions on energy and sustainable economic development for India [4]. Parikh et al. [5] evaluated the Indian subsector carbon emissions for 2003, but did not consider the future emissions and strategies.

A number of papers which were published in the journal edited by Parikh and Lior [4]. Parikh et al. [5] evaluated the Indian subsector carbon emissions for year 2003, but did not consider the future emissions. In recent years, Soytas et al., Soytas and Sari, Zhang and Cheng, Sari and Soytas, Halicioglu, Jalil and Mahmud, Ang [6-12] have studied the relationship between economic growth, carbon emissions, and energy consumption, by the use of 
the test empirical model. On the other hand, Sajal [13] used the multivariate cointegration analysis method to study the long-term, as well as short-term relationship between carbon emissions and economic growth in India. Another, Murthy, Manoj and Jyoti [14] studied the relationship between India's economic development and carbon emissions, based on the input-output (IO) model. Jyoti and Kirit [15] studied the India's energy needs and low carbon development strategy. Pao and Tsai [16] examined the dynamic relationships between pollutant emissions, energy consumption, and the output for Brazil during 1980 to 2007 by the use of Grey prediction model. Akay and Atak, Zhou and Ang $[17,18]$ forecasted the electricity demand using Grey prediction approach. Shukla et al. [19] have conducted some work on India's long-term energy demand and emissions forecasts, studies on sector-specific energy demand and emissions through key indicators development. Rout [20] studied the frame to forecast India's possible energy demands and emissions adopting a key indicator approach on least cost generation expansion optimization methodology.

The above studies focused on energy consumption and carbon emissions by the use of qualitative research or statistical model, which have limitations of no considering the balance economic growth hypotheses. Wang, Zhu and Liu [21] think that the above research can not reveal the mechanism of carbon emissions by the use of statistical models, and the statistical data limits the long-term extrapolation. However, the long-term extrapolation is necessary for studying the climate protection. For the estimation of a country's carbon emissions demands, the basic principle is to ensure balance economic growth. If only considering energy conservation, which will not only slow down economic development, but also will trigger the economic crisis. Therefore, taking the policy of carbon emissions reduction should base on the balance economic growth path. When the annual social welfare cumulative is maximized, economic growth will be in the balance orbit. Therefore, the authors predict India's energy consumption and carbon emissions demands for considering the condition of India's annual social welfare cumulative maximized. Therefore, based on the calculating carbon emissions formula from IPCC, economic dynamics model [22], energy intensity model and population growth model, the authors calculate the history total energy consumption demands and carbon emissions demands for time span 1980-2008. And then, the authors predict the future energy consumption demands and carbon emissions demands from 2009 to 2050 under the optimal economic growth path in India.

The paper is divided into four sections and rest of the paper is as follows. Section 2 contains the model and key data. Analysis of the results of India's history and future of energy consumption and carbon emissions are in Section 3. Final section presents the conclusions drawn from the study and recommendations.

\section{Model and Data}

\subsection{Data Source}

According to the research plan, the relevant data includes real gross domestic product (GDP), real capital stock, the total population, labor force and sub-species of energy consumption for time span 1980-2008 in India. The total population and labor force data have been collected from the World Bank. The data of energy consumption is from the US Energy Information Administration. The energy data includes the amount of coal, oil, natural gas and electricity consumption.

\subsection{Economic Dynamics Model and Parameter Estimation}

In this paper, the basic models are Cobb-Douglas production and Cross time optimization model from the literature [21,23], which are based on economic dynamics and optimal control theory. Zhu, Wang et al. [23] have improved the model as an energy economy model under the sustained and balance economic growth path, the formula is written as:

$$
\begin{aligned}
g= & (n-\rho / \sigma) \\
& +(1 / \sigma)(\varepsilon-\theta \tau)\left(A_{0} e^{v t}\right)^{1 / \alpha} \tau^{(1-\alpha) / \alpha}\left(w N_{0} e^{n t}\right)^{\gamma / \alpha}
\end{aligned}
$$

where $g$ represents the optimal rate of economic growth. $\tau$ is the energy intensity. $N_{0}, n, w$ are the amount of base year population data, population growth rate and labor force participation rate, respectively. $\rho, \sigma$ are the utility function parameters. $\varepsilon$ is the depreciation of the remaining ratio. $\theta$ is the energy comprehensive cost. $A_{0}$ and $\alpha$ are the initial level of total factor productivity and growth rate, respectively. $\alpha$ and $\gamma$ are the output elasticity of capital and labor, separately.

Balance economic growth path is a growth trajectory where all variables grow at constant rates. It will not make economic crisis caused by energy saving. This paper uses a comprehensive production function, which implies that energy structure and industrial structure changes are shown by the mean of the general technical progress. This optimum is defined as members of society in future consumption brought about the present value of maximum utility, that is:

$\max \int_{0}^{\infty} U[C(t)] e^{-\rho t} \mathrm{~d} t=\int_{0}^{\infty} e^{-\rho t}\left(C^{1-\sigma}-1\right) /(1-\sigma) \mathrm{d} t$

where $C$ represents the total social consumption. $\sigma$ is the risk aversion coefficient ( $\sigma^{-1}$ is the inter temporal substitution elasticity of consumption). $\rho$ is the rate of time preference. Basing on this model, we think that estimation of India's future carbon emissions demands is- 
equal to the forecast of India's future carbon emissions under optimal balance growth path. The forecast of India's future carbon emissions demands is the results based on dynamic analysis, so it will meet developing needs condition and ensure balance growth.

Based on the Equation (1), this paper calculates the India's optimal economic growth and the total GDP under the best economic growth path during 2009-2050. The carbon emissions calculation process is shown in Figure 1. While calendar year GDP multiplied by the energy intensity, we will get the amount of the annual energy consumption. And then, combination of future energy mix and sub-species energy carbon emissions factor, carbon emissions demands will be got from 2009 to 2050. In order to get India's future energy consumption and carbon emissions demands for each year, this paper needs to calculate the annual India's best economic growth based on Equation (1). Therefore, we firstly estimate the parameters for the Equation (1). The initial total factor productivity and growth rate, as well as capital and labor output elasticity can be estimated by the production function. Involving with population growth and energy intensity of inputs, the production function can be written as:

$$
\begin{aligned}
& Y(t)=\left(A_{0} e^{v t}\right)^{1 / \alpha} \tau(t)^{(1-\alpha) / \alpha}\left(\omega N_{0} e^{n t}\right)^{\gamma / \alpha} K(t) \\
& 0<A<1, \quad 0<\alpha<1
\end{aligned}
$$

where $Y(t)$ is the total output for the community. $A_{0}$ is the initial level of total factor productivity. $v$ is the total factor productivity growth rate. $\tau(t)$ is the energy intensity, $N_{0}$ is the total population of the community.

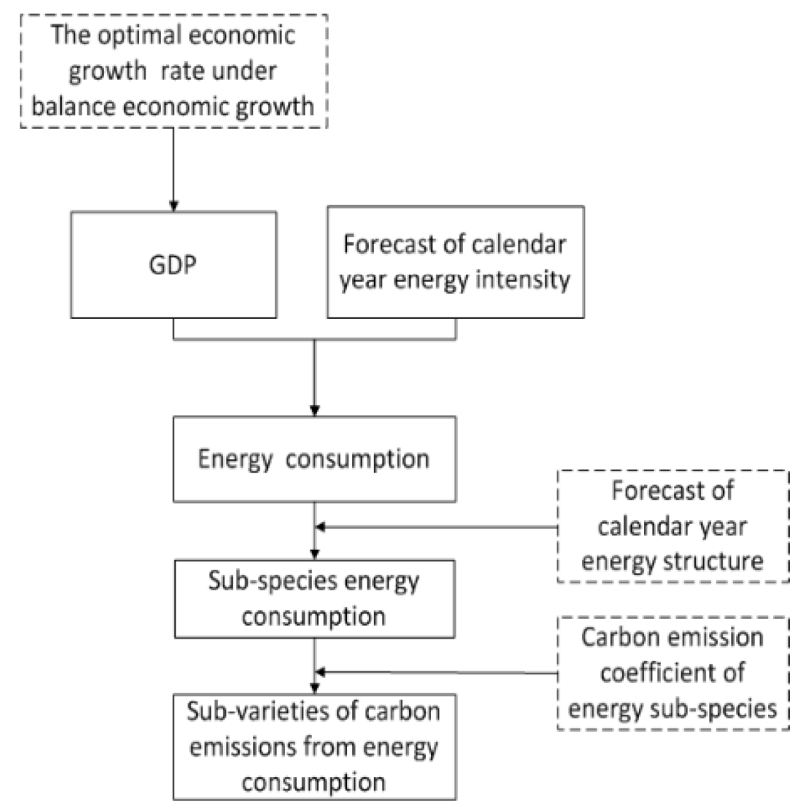

Figure 1. The calculation flow of carbon emissions demands. $\omega$ is the labor force participation rate (the proportion of the total population employed). $n$ is the average annual growth rate for the future population. $K(t)$ is the physical capital investment. $\alpha$ is the capital-output elasticity. $\gamma$ is the labor output elasticity.

Basing on Cobb-Douglas function transformation, the Equation (3) can be written as:

$$
Y^{\prime}=a_{0}+v t+a K^{\prime}+\gamma L^{\prime}+\varepsilon
$$

where

$$
Y^{\prime}=\ln (Y / E), a_{0}=\ln \left(A_{0}\right), K^{\prime}=\ln (K / E), L^{\prime}=\ln (L) .
$$

The meaning of each parameter is the same as the Equation (3).

Economic output data can be represented by the India's GDP, which is collected from the World Bank. Accounting for capital stock, it is derived from the Indian calendar year gross capital formation and depreciation. The calculation of GDP and capital investment are in 2000 constant prices. Labor force data is presented by the year-end number of India's employees from the World Bank database. Energy consumption data is from the US Energy Information Agency (IEA).

This paper takes the data of 1990 to 2008 time series of India's economic variables as the sample data. According to the actual time series data fit results, this paper sets the value of technological progress rate to 0 . Regression results are shown in Table 1. We found that there is a very good fit degree for Equation (4) $\left(R^{2}=0.9\right)$, and the parameter values are significant in the $10 \%$ level.

The assumption is that the forecast of economic growth and real economic growth need to be as consistent as possible. Then, according to the actual data of India 1993-2008 real GDP, economic growth, energy intensity, energy consumption and labor force, we adjust the $\sigma$ value of 2.3, $\rho$ value of 0.03 . For the depreciation rate $\varepsilon$, this paper sets the value of $\varepsilon$ to 0.904 , according to Zhang et al. [22].

The comparison of simulation results with India's actual economic growth rate is shown in Table 2. We found that the theoretical optimal economic growth rate is very close to the actual value. To a certain extent, it explains that the simulation is reasonable. However, this simulation is the optimal growth under balance economic growth conditions. The reality economic state is often affected by many factors. So there is a certain gap between the actual and simulation results.

Table 1. Estimation results of parameters in production function.

\begin{tabular}{cccc}
\hline Parameter & Parameter value & T value & Significance level \\
\hline$a_{0}$ & 18.949 & 2.221 & 0.045 \\
$\alpha$ & 0.650 & 2.832 & 0.014 \\
$\gamma$ & -1.677 & -1.813 & 0.093 \\
\hline
\end{tabular}


Table 2. Comparison of the growth rate of actual economy with the simulated one during 2005-2009.

\begin{tabular}{cccc}
\hline Year & $\begin{array}{c}\text { Real economic } \\
\text { growth rate (\%) }\end{array}$ & $\begin{array}{c}\text { Optimal economic } \\
\text { Growth (\%) }\end{array}$ & $\begin{array}{c}\text { Growth rate } \\
\text { Gap (\%) }\end{array}$ \\
\hline 2005 & 9.30 & 10.41 & -1.10 \\
2006 & 9.44 & 9.95 & -0.51 \\
2007 & 9.63 & 9.52 & 0.11 \\
2008 & 5.12 & 9.11 & -3.99 \\
2009 & 7.66 & 8.75 & -1.09 \\
\hline
\end{tabular}

\subsection{IPCC Carbon Emissions Model}

In this paper, the authors estimate the amount of carbon emissions according the IPCC guidelines [24]. India's coal reserves ranked fourth in the world [25]. India's energy resources is dominated by coal, accounting for $96 \%$ of the total energy Source. The oil and natural gas each accounted for $2 \%$ [26]. The carbon emissions in atmospheric mainly come from fossil energy consumption. The use of wind energy, hydropower, atom energy would produce a small amount of carbon dioxide or even not. And the India's currently main energy consumption includes coal, oil, natural gas. Therefore, the authors only consider carbon emissions from energy consumption in India. Therefore, this article only calculates and predicts the carbon emissions from coal, oil, natural gas consumption. The formula is:

$$
Q=\sum_{i=1}^{3} C_{i} \times X_{i}
$$

where $Q$ represents carbon emissions $\left(10^{6}\right.$ tons of carbon emission: Mt C); $C_{i}$ is consumption of $i$ energy, according to the standard oil calculated (million tons of oil equivalent: Mtoe ); $i$ is the energy type, including coal, oil, natural gas; $X_{i}$ is coefficient of energy carbon emissions. In this paper, the carbon emissions coefficients of coal, oil, natural gas are respectively 1.0052, $0.753,0.6173$ (unit of standard oil to released carbon equivalent) [23].

\subsection{Energy Intensity Model}

Energy intensity is defined as the energy input divided by the economic output. It may be written as follows:

$$
\tau=E / Y
$$

where $\tau$ is the energy intensity. $E$ is the energy input. $Y$ is the economic output, which represents the real GDP. Fitting the India's energy intensity data from 1990 to 2008, we found that it decreases exponentially. The equation is:

$$
\tau_{t}=b_{0} e^{b_{1} t} \quad t=1 \cdots n
$$

According to Equation (7), we can predict the future annual energy intensity. Combination Equation (6) and Equation (7), through the regression derivation analysis of the India's energy consumption data and economic output data during 1980-2008, we get the India's energy intensity Equation (8).The equation is:

$$
\begin{aligned}
& \tau_{t}=0.00951 e^{-0.02 t} \\
& t=1 \cdots n \quad R^{2}=0.93
\end{aligned}
$$

where $\tau_{t}$ is the annual energy intensity.

\subsection{Logistic Model}

According to Equation (1), in order to get the India's future optimal economic growth, we need to get the India's annual population growth rate and the total population. In recent years, India's population increases rapidly. In 1980, the total number of population is was 684 million. In 2010, the total number of population reached over 1230 billion. The population growth cannot be endless. Therefore, this article uses Logistic method to predict the population in India from 2009 to 2050.

Logistic growth equation is known as growth function, reflecting the population growth characteristics of competition. When the biomass is close to the capacity of the environment, the growth rate will slow down or even stop growth. The curve of the performance is " $\mathrm{S}$ " shape. It is also known as " $\mathrm{S}$ " the curve. The form is:

$$
y_{t}=k /\left(1+a e^{-b t}\right)(k>0, a>0,0<b \neq 1)
$$

where $y_{t}$ is the population data in t year. $k$ is the limits value under population saturation situation. $a$ and $b$ are constant parameters. We find a appropriate upper limit $k$, and $a$ and $b$ can be got by using SPSS statistical software curve fitting. Then we can build the India's population growth model. The equation can be written as:

$$
y_{t}=2000 /\left(1+0.001 e^{-0.967 t}\right)
$$

The equation overall fit is very good. The various parameters are through a 0.01 significance test.

\section{Results}

\subsection{Historic Trend of Energy Consumption Carbon Emissions}

From 1995 to 2008, India's average annual economic growth rate is $6.85 \%$. The faster the economic develop, the greater the energy demand. In 1995, the amount of energy consumption was 288.35 Mtoe in India. Then, it increased to 502.84 Mtoe in 2006. The average annual growth rate is $5.17 \%$, which is higher than world average energy consumption growth rate of $1.4 \%$. High energy consumption 
impacts on adequately higher emission of greenhouse gases into the Earth's atmosphere. In 1995, Carbon emissions was $240.95 \mathrm{Mt}$ C. Then, it increased to $414.60 \mathrm{Mt}$ $\mathrm{C}$ in 2008. The average annual growth rate is $9.08 \%$ from 1995 to 2008. The comparisons between carbon emissions and energy consumption are shown in Figure 2. Carbon emissions and energy consumption are in the same growth trend since 1995. And energy consumption and carbon emissions have grown significantly.

\subsection{Energy Structure Prediction}

Using of the India's sub-varieties of energy consumption data and the total energy consumption data, the authors calculate the energy structure in India from 1980 to 2008, which is shown in Figure 3. During 1980-2008, the share of coal has remained at 55\% in India's energy consumption structure. However, the oil proportion fluctuates severely. In 1994, the share of oil decreases to $24.59 \%$. But, in 1995, the proportion of oil rises to $29.25 \%$. The reasons are that India is lack of energy resources and heavily dependent on energy imports. At the same time, International crude oil prices have been in the state of fluctuations. The proportion of natural gas has remained in a steady upward trend. In 1980, the share of natural gas was $1.52 \%$. Then the share of natural gas rises to 7.88\% in 2008.

According to the Markov chain method, we can get probability transition matrix and predict India's energy structure from 2009 to 2050, which is shown in Figure 4. After 2017, the share of India's coal, oil, natural gas are in a stable situation. The proportion of coal has remained at around $57 \%$. The proportion of oil has remained at around $26 \%$. The proportion of natural gas has remained at around $0.05 \%$. This is relative to continuously energy policy adjustment from the India's government, which includes increasing oil and gas production, the establishment of oil reserves strategy, developing other energy sources and carrying out the positive energy foreign policy.

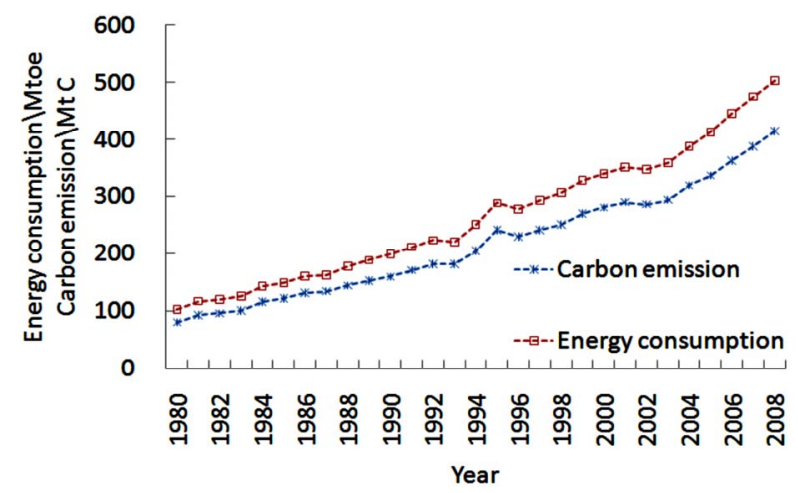

Figure 2. Gross energy consumption and carbon emissions between 1980 and 2008.

\subsection{Trend Analysis of Energy Consumption Carbon Emissions}

\subsubsection{The Comparison Analysis of Simulation Results with India's Actual Carbon Emissions}

The comparison of simulation results with India's actual energy consumption carbon emissions is shown in Table 3. We find that the theoretical carbon emissions is very close to the actual value. To a certain extent, it explains that this estimate is reasonable. However, this simulation carbon emissions is based on balance economic growth conditions. The reality economic is often affected by many factors. So there is a certain gap between the real

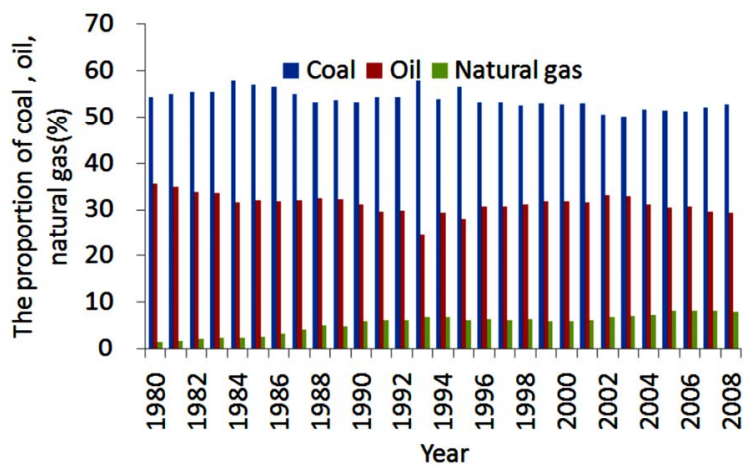

Figure 3. Comparison of energy consumption structure during 1980-2008.

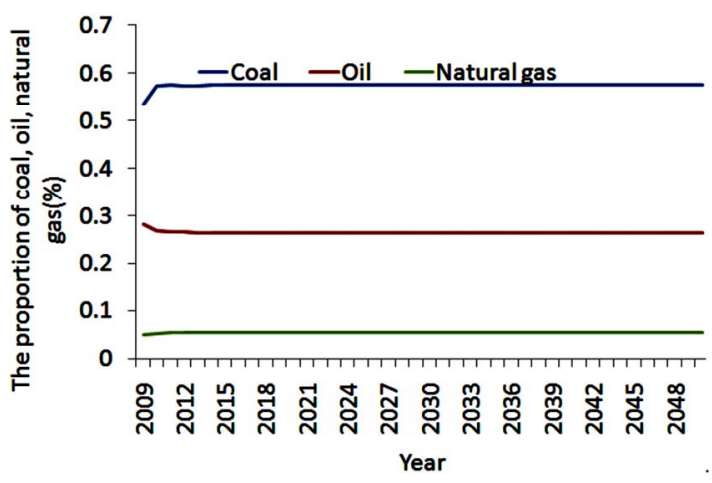

Figure 4. The trend of energy consumption structure from 2009 to 2050.

Table 3. Comparison of the energy consumption carbon emissions with the simulated one during 2005-2009.

\begin{tabular}{cccc}
\hline Year & $\begin{array}{c}\text { Real carbon } \\
\text { emissions (Mt C) }\end{array}$ & $\begin{array}{c}\text { Predication carbon } \\
\text { emissions (Mt C) }\end{array}$ & Gap (Mt C) \\
\hline 2005 & 322.71 & 332.17 & -9.45 \\
2006 & 349.82 & 359.27 & -9.45 \\
2007 & 373.20 & 383.47 & -10.28 \\
2008 & 399.08 & 423.59 & -24.51 \\
2009 & 433.94 & 430.82 & 3.12 \\
\hline
\end{tabular}


data and prediction data.

\subsubsection{Estimation of Energy Consumption}

Based on the energy intensity Equation (8), we find that the decline rate of India's energy intensity is 0.02 , and energy intensity declines exponentially from the year 1980 to 2008. According to the Equation (8), it is easy to calculate the energy intensity during 2009-2050. Combination of Equations (1) and (3) allows estimating the annual optimal economic growth and economic output. Then, we can get the annual total number of energy consumption by multiplying GDP and energy intensity under the optimal economic growth. The results are shown in Table 3. As can be seen from Table 3, firstly, the energy consumption increased from 2010 to 2045, and then it was falling after 2045. This is because that the industrial structure has the intrinsic inertia characteristic, and energy consumption growth will remain in a certain period of time, but eventually decline. Firstly, this is owing to the energy consumption gradually decreasing. Secondly, India government implements alternative energy policy and improves energy utilization. Reduction of the amount of input energy, to some extent, slows down the economic growth. Its expression is that the optimal growth rate is gradually declining.

\subsubsection{Trend Analysis of Carbon Emissions Demands}

The prediction results of India's annual energy structure during 2009-2050 are shown in Figure 5 by the use of Markov chain method. The calendar year energy consumption multiplied by the energy structure. Then we can get the sub-species of energy consumption when annual energy consumption is multiplied by the energy structure. Afterwards, sub-species of energy consumption is multiplied by respective carbon emissions factor. Then, the sub-species of energy carbon emissions could be got. The sum of annual sub-species of energy carbon emissions is the India's annual demand for carbon emissions for the time span 2009 to 2050. The results are shown in Figure 5.

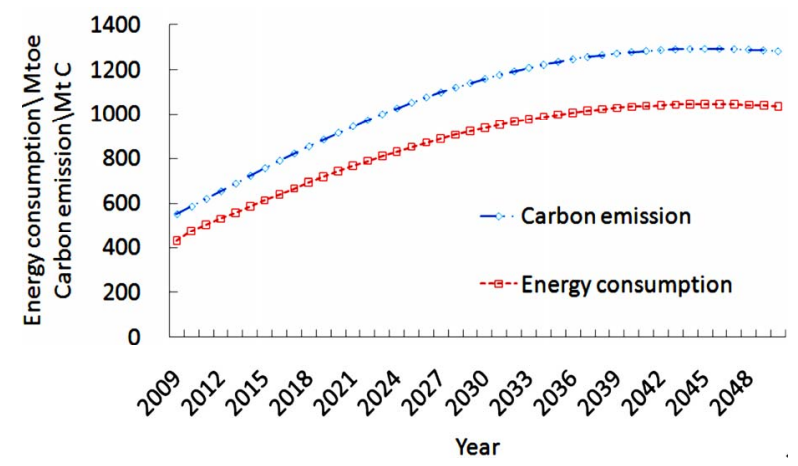

Figure 5. Comparison of the trend of energy consumption and carbon emissions during 2009-2050.
As can be seen from Figure 5, the India's energy consumption demands and carbon emissions demands firstly increase, and then show a downward trend. The demands value of energy consumption and carbon emissions reach to peak in 2045. Since 2045, they begin to fall. And the peak value of energy consumption demands is 1290.74 Mtoe. The peak value of carbon emissions demands is 1045.98 Mt C. The total amount of energy consumption demands is 44.65 Gtoe (109 tons of oil equivalent). The total amount of carbon emissions demands is $36.16 \mathrm{Gt} \mathrm{C}$ (109 tons of carbon emission). The distance between the two curves gradually widen. This is because that the proportion of high-carbon emissions energy is gradually decreasing, and low-carbon emissions energy proportion increases gradually. The increasing rate of carbon emissions is slower than the energy consumption increasing rate.

\subsubsection{Trend Analysis of Per Capita Energy Consumption and Carbon Emissions Demands}

By use of the logistic method, we predict the India's the annual total population from 2009 to 2050, based on the sample of India's population during 1980-2008. Through India's annual carbon emissions divided by the population, then we get the India's annual per capita carbon emissions demand. India's total energy consumption divided by the population, then the India per capita energy consumption demand can be got. The trend is shown in Figure 6.

Figure 6 shows that, since 2009, India's per capita energy consumption demand and carbon emissions demand are both gradually increasing. Up to 2037, per capita energy consumption demand reached a peak, the value of which is 0.81 (tons of standard oil/person). The per capita carbon emissions demand also exists a peak in 2037, and the peak value is 0.65 (tons carbon/person). After 2037, India per capita carbon emissions demand and energy consumption demand appear downward trend.

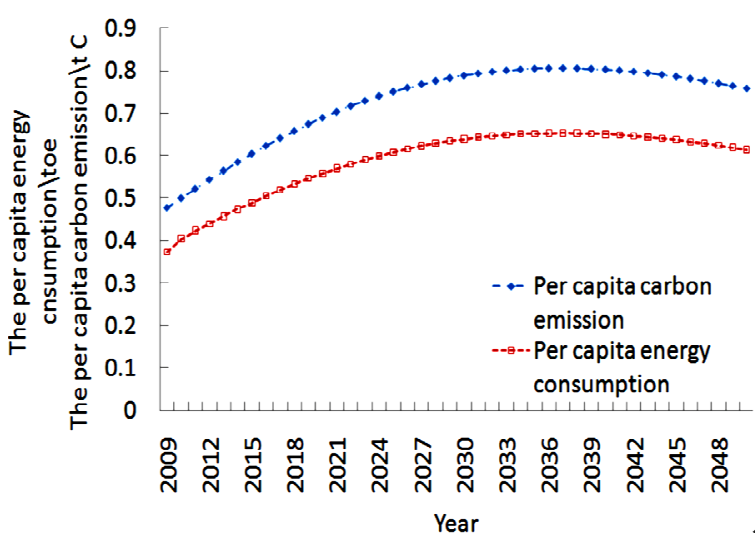

Figure 6. Comparison of the trend of per capita energy consumption and carbon emissions during 2009-2050. 


\section{Conclusions}

In this paper, combination of IPCC carbon emissions calculation model, the energy intensity model and economy-dynamic model, the authors firstly calculate the India's history energy consumption quantity and carbon emissions for time span 1980-2008. Then, the authors predict the India's 2009-2050 energy structure, energy consumption demands and carbon emissions demands. The study found:

1) From 1980 to 2050, the proportion of coal in India's energy structure has a little change, which basically maintains in range of $50 \%-55 \%$. Due to the impact of international crude oil price changes, the proportion of oil in India's energy structure fluctuate violently. In 1980, the proportion of oil accounted for the highest share of $35.53 \%$. On the contrary, the lowest proportion of oil is $24.59 \%$ in 1993 . In tested years, the proportion of gas in India's energy structure was unchanged.

2) From 2009 to 2050, the trend of India's energy consumption demand and carbon emissions demand were first in ascending and then gradually fall. They both have peak years. The peak demand of energy consumption exists in the year 2040. In the same year, the peak of carbon emissions was also observed.

3) 2009-2005, India's per capita energy consumption demand and per capita carbon emissions demand both firstly increased and then declined, which have homogeneous trend. In 2037, per capita energy consumption demand reached a peak, and the value was 0.81 (tons of standard oil/person). The peak value of per capita carbon emissions demand also exists in 2037. The value is 0.65 (tons carbon/person).

\section{Acknowledgements}

The authors would like to express appreciations to colleagues in our laboratory for their valuable comments and other helps. At the same time, this work was funded by the 973 project of Ministry of Science and Technology of China, Grant 2012CB955800 and by the CAS Strategic Priority Research Program, Grant XDA011505.

\section{REFERENCES}

[1] IPCC, "Climate Change 2007: Synthesis Report. Summary for Policymakers," Intergovernmental Panel on Climate Change Plenary XXVII, Valencia, 12-17 November 2007, 22 p.

[2] C. Rosenzweig, D. Karoly, M. Vicarelli, P. Neofotis, Q. Wu, G. Casassa, A. Menzel, T. L. Root, N. Estrella, B. Seguin, P. Tryjanowski, C. Liu, S. Rawlins and A. Imeson, "Attributing Physical and Biological Impacts to Anthropogenic Climate Change,” Nature, Vol. 453, No. 7193, 2008, pp. 353-357. doi:10.1038/nature06937

[3] P. T. Doran and M. K. Zimmerman, "Examining the
Scientific Consensus on Climate Change,” Eos, Transactions American Geophysical Union, Vol. 90, No. 3, 2009, p. 22. doi:10.1029/2009EO030002

[4] J. Parikh and N. Lior, "Energy and Its stainable Development for India,” Energy, Vol. 34, No. 8, 2009, pp. 923927.

[5] J. Parikh, M. Panda, A. Ganesh-Kumar and V. Singh, "CO $\mathrm{CO}_{2}$ Emissions Structure of Indian Economy," Energy, Vol. 34, No. 8, 2009, pp. 1024-1031. doi:10.1016/j.energy.2009.02.014

[6] U. Soytas, R. Sari and B. T. Ewing, "Energy Consumption, Income, and Carbon Emissions in the United States,” Ecological Economics, Vol. 62, No. 3-4, 2007, pp. 482-489. doi:10.1016/j.ecolecon.2006.07.009

[7] U. Soytas and R. Sari, "Energy Consumption, Economic Growth, and Carbon Emissions: Challenges Faced by an EU Candidate Member,” Ecological Economics, Vol. 68, No. 6, 2009, pp. 1667-1675. doi:10.1016/j.ecolecon.2007.06.014

[8] X. P. Zhang and X. M. Cheng, "Energy Consumption, Carbon Emissions, and Economic Growth in China," Ecological Economics, Vol. 68, No. 10, 2009, pp. 27062712. doi:10.1016/j.ecolecon.2009.05.011

[9] R. Sari and U. Soytas, "Are Global Warming and Economic Growth Compatible? Evidence from Five OPEC Countries?” Applied Energy, Vol. 86, No. 10, 2009, pp. 1887-1893. doi:10.1016/j.apenergy.2008.12.007

[10] F. Halicioglu, “An Econometric Study of $\mathrm{CO}_{2}$ Emissions, Energy Consumption, Income and Foreign Trade in Turkey," Energy Policy, Vol. 37, No. 3, 2009, pp. 11561164. doi:10.1016/j.enpol.2008.11.012

[11] A. Jalil and S. F. Mahmud, "Environment Kuznets Curve for $\mathrm{CO}_{2}$ Emissions: A Cointegration Analysis for China," Energy Policy, Vol. 37, No. 12, 2009, pp. 5167-5172. doi:10.1016/j.enpol.2009.07.044

[12] J. B. Ang, "Economic Development, Pollutant Emissions and Energy Consumption in Malaysia," Journal of Policy Modeling, Vol. 30, No. 2, 2008, pp. 271-278. doi:10.1016/j.jpolmod.2007.04.010

[13] G. Sajal, "Examining Carbon Emissions Economic Growth Nexus for India: A Multivariate Cointegration Approach," Energy Policy, Vol. 38, No. 6, 2009, pp. 30083014. doi:10.1016/j.enpol.2010.01.040

[14] N. S. Murthy, P. Manoj and P. Jyoti, "Economic Development, Poverty Reduction and Carbon Emissions in India,” Energy Ecconomics, Vol. 19, No. 3, 1997, pp. 327-354. doi:10.1016/S0140-9883(96)01021-3

[15] P. Jyoti and P. Kirit, "India's Energy Needs and Low Carbon Options," Energy, Vol. 36, No. 6, 2011, pp. 3650-3658. doi:10.1016/j.energy.2011.01.046

[16] H. T. Pao and C. M. Tsai, "Modeling and Forecasting the $\mathrm{CO}_{2}$ Emissions, Energy Consumption, and Ecnomic Growth in Brazil,” Energy, Vol. 36, No. 5, 2011, pp. 24502458. doi:10.1016/j.energy.2011.01.032

[17] D. Akay and M. Atak, "Grey Prediction with Rolling Mechanism for Electricity Demand Forecasting of Turkey," Energy, Vol. 32, No. 9, 2007, pp. 1670-1675. doi:10.1016/j.energy.2006.11.014 
[18] P. Zhou, B. W. Ang and K. L. Poh, “A Trigonometric Grey Prediction Approach to Forecasting Electricity Demand,” Energy, Vol. 31, No. 14, 2006, pp. 2839-2847. doi:10.1016/j.energy.2005.12.002

[19] P. R. Shukla, R. Nair, M. Kapshe, T. Hamacher, T. Kram, A. J. Seebregts and K. E. L. Smekens, "Long-Term Energy Scenarios for India," A Report of the Collaborative Project between Indian Institute of Management, Ahmedabad, 2002.

[20] U. K. Rout, "Prospects of India's Energy and Emisions for a Long Time Frame,” Energy Policy, Vol. 39, No. 9, 2011, pp. 5647-5663. doi:10.1016/j.enpol.2011.04.026

[21] Z. Wang, Y. B. Zhu, C. X. Liu and X. Z. Ma, “Integrated Projection of Carbon Emissions for China under the Optimal Economic Growth Path,” Journal of Geographical Science, Vol. 65, No. 12, 2010, pp. 1559-1568.
[22] J. Zhang, G. Y. Wu and J. P. Zhang, "The Estimation of China’s Provincial Capital Stock: 1952-2000,” Economic Research Journal, Vol. 10, 2004, pp. 35-44.

[23] Y. B. Zhu, Z. Wang, L. Pang, L. J. Wang and X. P. Zhou, "Simulation on China's Economy and Prediction on Energy Consumption and Carbon Emissions under Optimal Growth Path,” Acta Geogrephica Sinica, Vol. 8, 2009, pp. 935-944.

[24] IPCC, “2006 Intergovernmental Panel on Climate Change Guidelines for National Greenhouse Gas Inventories: Volume II ,” 2008. http://www. ipcc.ch/ipccreports/Methodology-reports.htm

[25] BP, "World Energy Statistics,” 2008. http://www.bp.com/statisticalreview/

[26] IEA, “Annual report of the World Energy Organization,” 2007. http://www.iea.org/Textbase/stats 